\title{
Integrated Open Source Design for Architecture in High-Density Housing Practice
}

\author{
Yan $\mathrm{Gao}^{1}$, Xin Guo ${ }^{1,2}$, Tiantian $\mathrm{Lo}^{3}$ and Qiang Chang ${ }^{4}$ \\ 1. Department of Architecture, University of Hong Kong, Hong Kong 999077, China \\ 2. College of Architecture and Urban Planning, Shenzhen University, Shenzhen 518053, China \\ 3. School of Architecture, Chinese University of Hong Kong, Hong Kong 999077, China \\ 4. International Research Centre of Computational Design, Tsinghua Architectural Design \& Research Institute, Beijing 100084, \\ China
}

\begin{abstract}
High-density housing can be interpreted as collections of individual units, which inevitably results in the dilemma between the global standardization designed by architects and local customization implemented by users. However, it is impossible to reflect the users' various needs in the conceptual design stage for high-density housing because of the economic, industrial and time constrains. In response to this challenge, this research paper outlines a different high-density housing design approach that can adopt users' individual customization in the conceptual design stage during the housing design practice. Hence, the design process would be an open-ended evolutionary and transparent process rather than deterministic executions as we have now in most high-density cities, such as Hong Kong. In order to overcome the deficiency in addressing future uncertainties of different users and address the issues of one-off developments without iterating users' feedback in the housing practice, this essay proposes IOSDA (integrated open source design for architecture) for the design practice of high-density housing, through collective data and parametric connectivity between users and architects. IOSDA reflects a different design attitude towards the future, i.e., to shift from architects' heroic prediction of the future to collective engagement of the present with more robust capacities for new possibilities.
\end{abstract}

Key words: Open source architecture, high density, urban transformation, plug-in infrastructure, smart BIM, iterative design, parametric crowd, network thinking.

\section{Introduction}

In product development, open source as a philosophy promotes a universal access via free license to a product's design or blueprint, and universal redistribution, including subsequent improvements to it by anyone [1]. Opening the source codes enables diversified customization to further develop the original products against the limitation of the initial version of the product, which is the basis of the collective intelligence for innovation. Open source has been nurturing the IT (information technology) industry for developing programs and breeding different virtual communities according to the

Corresponding author: Yan Gao, assistant professor, research field: computation in contemporary design. E-mail: yangao@hku.hk. particular source codes.

OSA (open source architecture) is an emerging paradigm that advocates new procedures in imagination and formation of virtual and real spaces within a universal infrastructure. ${ }^{1}$ Drawing from references as diverse as open-source culture, avant-garde architectural theory, science fiction, language theory and others, it describes an inclusive approach to spatial design, a collaborative use of design software and the transparent operation throughout the course of a building and city's life cycle. $^{2}$

In the architectural field, the ideas and the approaches of open source design have been borrowed

\footnotetext{
${ }^{1} \mathrm{http} / / /$ en.wikipedia.org/wiki/Open-source_architecture.

${ }^{2} \mathrm{http}: / /$ www.domusweb.it/en/op-ed.html.
} 
for years. But it could not be applied to the mainstream of architectural practice due to the complexity of the architectural industry, including but not limit to design, procurement, construction and many other intertwined issues. The recent WikiHouse ${ }^{3}$ could only deal with the simplest house solutions instead of exploiting the complexity of collective design including participation of the end users for high density housing, which is the type of architecture that needs negotiation among multiple users, architects and stake holders.

The essential objective of this research paper is to establish the theoretical framework for IOSDA (integrated open source design for architecture), a new paradigm of housing design practice based on collective data and parametric connectivity.

\section{Issues and Problems in the Current Housing Design Practice}

Architectural design is always the derivative work of the sources from others to some extent. Drawings and blueprints are the primary source codes for architects. Different architectural ideologies are somehow like different program languages, e.g., VB, Java, C\#, each of which has its own syntax and vocabulary. Equally, they all create their own tribe's sharing and customizing the published source code to be an individual building according to specific context such as the users' needs and the environmental conditions. Today, the written architectural source code has been extended to both end users and stakeholders beyond architects, such as WikiHouse. Open source architecture challenges the necessity of architects in the house design chain.

Nevertheless, architects do not have to be panic. Building is significantly different from computer systems. There is still a long way to go before users can deliver autonomous architectural designs by composing architectural source codes without architects. Especially for housing design, there must

\footnotetext{
${ }^{3}$ http://www.wikihouse.cc.
}

be a balance between top-down synthetic control and bottom-up systematic customization. To control the uncontrollable is thus the art of IOSDA.

\subsection{Financial Risks in Traditional Housing Supply Chain}

In the conventional housing supply chain, the investors always take the financial risks of housing projects, hoping that their prediction upon the market analysis of the past would work. However, the prediction is often frustrated by the delayed reaction in a volatile market. The housing products might already be depreciated during the construction period. Risks will be higher if the housing takes longer before completion. This is why many developers in China are always rushing for the rapid completion.

\subsection{Lost of Individuality in the Uniform Living} Environment

In the conventional high-density housing market, users can only choose from what have been predetermined by developers or governments. The development of digital technologies should allow a more humanistic design approach in favour of individual expression. The current high-density housing procurement model is still based on the top-down design methodologies, in which the developers are the ultimate decision makers to determine your home space and layout in the first place: the users can only pick one out of the many same units as their own home. The quality of vernacular housing, i.e., the collective harmony of differentiation with the individual expression at the fundamental level of space and layout, through the particular process of making their own houses according to the established building codes, has been completely lost in the dense urban environment because of the vacuum of individual participation during the conceptual design stage.

\subsection{Stringent Statutory Building Code}

The important merit of vernacular architecture is its 
collective beauty of individual customization based on the shared principles in tectonics and materials. Whereas in high-density housing design, the statutory building codes are always regarded as counter-productive design constrains, suppressing creative design opportunities. Effective building codes ensure efficiency and fitness of housing products. Meanwhile, it also discourages risk takers for new design possibilities. Building codes are often presented as fixed facts. The initial purposes of some statutory building codes need to be revisited. Defining the source codes that regulate the statutory codes would liberate architects in the housing sector from technical productivity and surface decoration to productive design creativity, focusing more on the relationships between parts rather than the static composition of definite building elements.

The building codes for housing in Hong Kong are very sophisticated. They are written in such a way that you cannot fully interpret them unless you have practiced in Hong Kong for years. Considering the fact that even the professionals cannot easily handle the current building codes, the verification of individual design customization in OSA will be an impossible task, unless the building code auditing processes can be automated through some computational processes, so that the time-consuming repetitive checking of every different units within a range of possibilities can be done with a click.

Fig. 1 shows the parametric checking of the prescribed
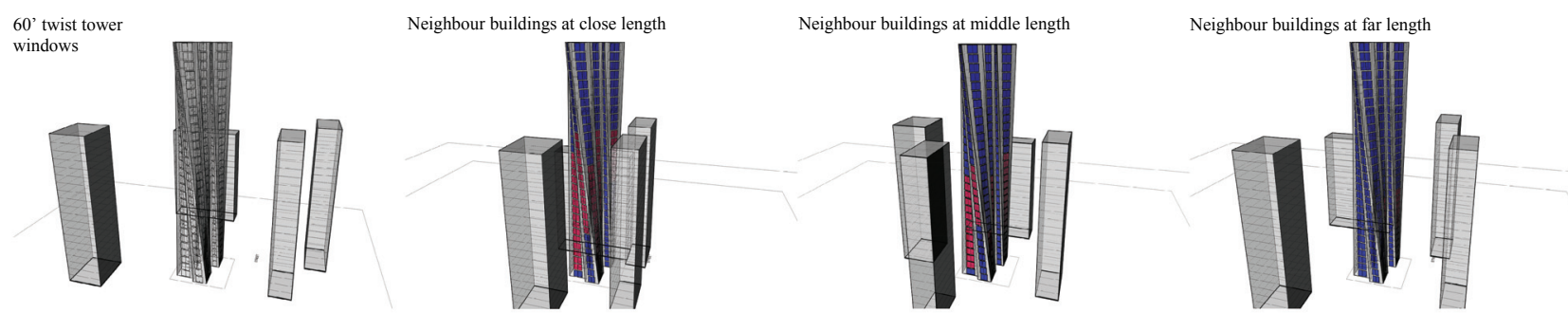

No twist tower

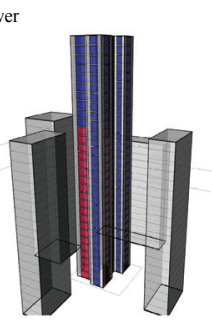

$30^{\prime}$ twist tower

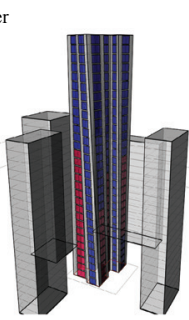

$40^{\prime}$ twist tower

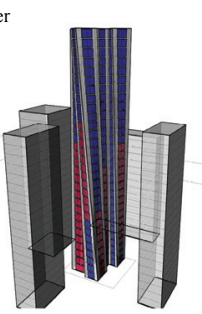

60 ' twist tower
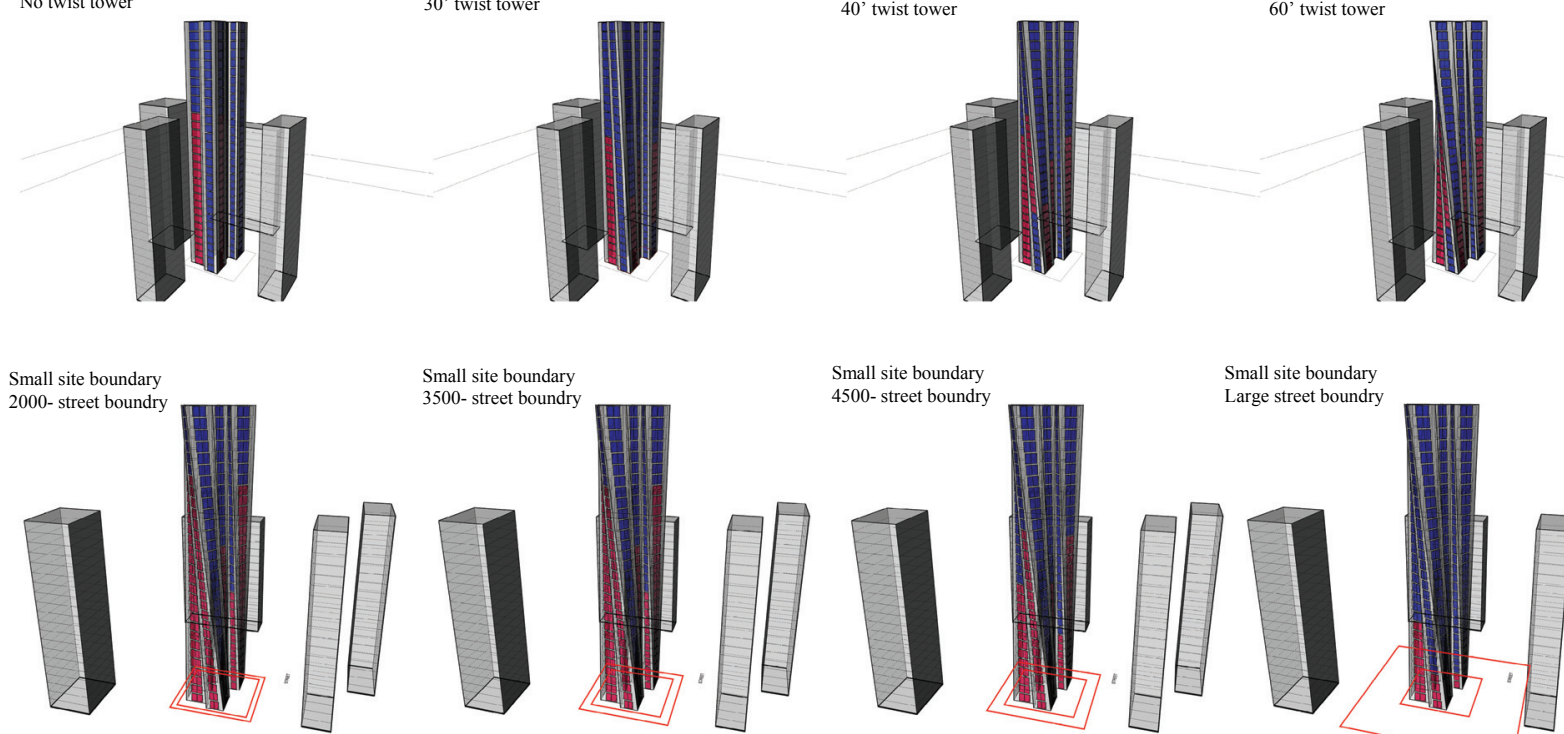

Small site boundary

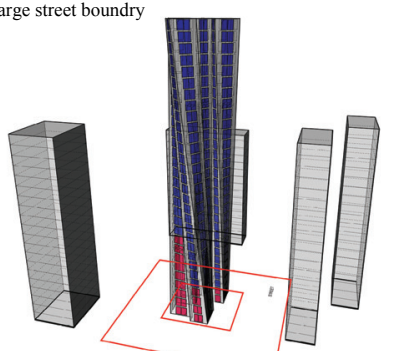

Fig. 1 Parametric simulation of the Hong Kong Housing Building Code for prescribed windows through dynamic context and building conditions. 
windows defined by the statutory building code ${ }^{4}$ with changing conditions. It proved that the statutory building codes can be simulated as dynamic references allowing a big number of varieties, instead of being the constrains for the large housing products everywhere in Hong Kong at present.

\subsection{Problems of One-Off Design Methodologies for Conventional Housing Design in Addressing Future \\ Uncertainties}

The problems of the one-off design methodologies in conventional architectural design have been widely criticized by many scholars [2] due to the cost to adapt to the future changes, powerless to address every individual needs during the initial design stage. In practice, the one-off design methodologies still dominate the architectural practice, especially in the high-density housing. Both the missing theories and the lack of cost-effective design imperators are the main hurdles.

\footnotetext{
${ }^{4}$ According to the building code issued by Hong Kong Housing Department, the prescribed windows are: (1) faces street not less than $4.5 \mathrm{~m}$; (2) faces uncovered and unobstructed area above a rectangular horizontal plane; (3) if another rectangular plane, the base whereof is equal to and common with the base of the rectangular horizontal plane, is inclined, above the rectangular horizontal plane, at an angle of $71.5^{\circ}$ from the horizontal where the window is in a room used for habitation or $76^{\circ}$ from the horizontal where the window is in a room used for the purposes of an office or as a kitchen, no part of the building, or of any other building within the site on which such building is erected, protrudes above such plane; (4) where such window opens on to an area bounded on the side opposite the window by a boundary of the site on which the building is erected, such window is so placed that, if the rectangular horizontal plane Cap 123F-Building (Planning) Regulations 12 is projected to such boundary and, from the position at which it first intersects the boundary, another rectangular plane, the base whereof is parallel and level with the sill of the window and has a length equal to the length of the base of the rectangular horizontal plane, is projected, towards the site and above the rectangular horizontal plane, at an angle of $80.5^{\circ}$ from the horizontal where the window is in a room used for habitation or $83^{\circ}$ where the window is in a room used for the purposes of an office or as a kitchen, no part of the building, or of any other building within such site, protrudes above such inclined plane; (5) provided that, where there is a service lane or street less than $4.5 \mathrm{~m}$ wide adjacent to and parallel with such boundary, the boundary shall, for the purposes of this sub-paragraph be deemed to be at a position $1.5 \mathrm{~m}$ beyond such boundary.
}

\subsection{Main Problems of Bottom-Up Design Approaches}

Bottom-up or self-organized systems are becoming more fashionable in architectural design when the young generations grasp the parametric modeling tools. There is no doubt that they have challenged the established top-down design approaches. However, the new problems arise. First of all, the bottom-up approach is meant to maximize the satisfaction of individual needs because of its power to process mass data, whereas it has become the seduction for architects to realize their own formal obsessions on the visual complexity for the sake of complexity. Secondly, many outcomes based on the bottom-up approaches are lack of the synthesis of addressing real complex issues through design intelligence. Such phenomena actually create the equivalent sameness as the modernism has ever pronounced the international styles. No matter how surprising the form may be, it always repeats the familiar complex geometries, such as continuous differentiations on three-dimensional surface [3].

The design authors in the bottom-up design process are still individual architects. Although we recognize the team collaboration in contemporary architectural practice, how to encourage the diversity and the new possibilities based on multiple individual design team members in the hierarchical design practice is yet to be investigated. Only by then can we achieve the collective intelligence for more adaptive design, balancing the top-down visions and the bottom-up responses.

\subsection{High-Density Housing Evolution through Feedback of Users}

Architects' mission often terminates when a professional photographer takes shining photos before users' occupation. The investors wrap up with their profit and hand over to another operation company. The end users are the last ones who arrive at the "party" when most hosts have left. The process is so 
market driven that the sale record primarily evaluates the design success. The design reiterates itself with little timely feedback from end users. The current design mechanism of housing procurement is not able to incorporate users' feedback for design improvement and adjustment. There are also no practical design mechanisms for collecting and interpreting the feedback data as part of the design input for the successive housing design. Significant price has to be paid to learn lessons from the realities if we do not integrate users' feedback for the next versions of housing design.

\section{Open Source Design as a New Opportunity}

Open source architecture has been discussed for many years but few have realized any built projects, especially in the field of collective housing practice. The Next 21 Project in Japan is a rare case in applying open source design to the collective housing projects.

\subsection{Precedent Project: Next 21, Osaka, Japan}

The Next 21 Project (Fig. 2) is an experimental multi-family housing project demonstrating the new concept of multi-family housing that incorporates open design methods and advanced technologies that are expected to work in the near future. The building consists of 18 individual housing units, which were designed by 13 different architects. For this project, the focus is more on the building system itself instead of the collaboration process as compared to the previous example. Specific design strategies are generated from the framework of two principal concepts, the system building and the two-stage building.

The building is an integration of systems that were assembled from a series of multiple independent sub-systems, namely structure, cladding, infill and plumbing, so that the prefabricated components could be replaced easily and economically during the occupancy.

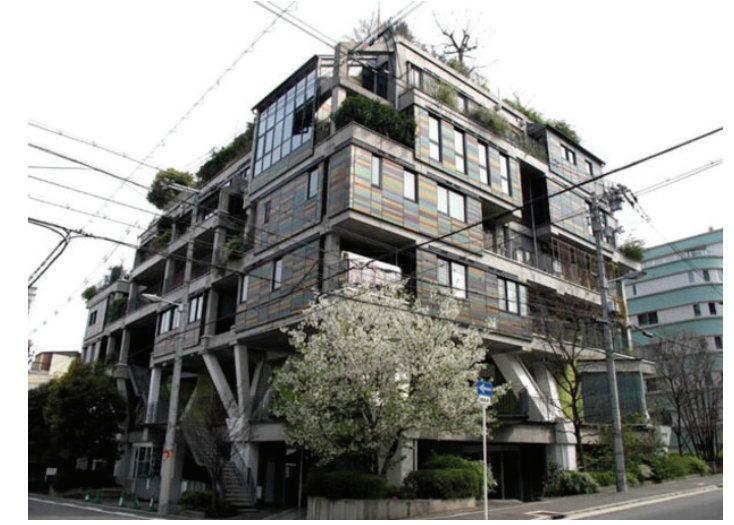

Fig. 2 The Next 21 Project.

The building strategy comprises two stages. The first was classifying the building into two groups: infrastructure which refers to shared elements including structure, cladding and plumbing, and infill which has individual properties including partitions, fitting and interior finishes. The second was the design process that was broken into two groups: One of which conducted interviews to identify the needs and desires of the prospective occupants in the collective housing, while the other group was responsible for designing the building structure that accommodated various unit cluster design and changes in time.

The Next 21 Project is one of the most comprehensive buildings that demonstrate and experiment open design methods during the conceptual design stage. In 1996, they did an experimental remodeling of one unit with the participation of its residents, which was a great success [4]. This provides precedence for the possibility of a participation/collaboration design method and also flexible building system for collective housing.

\subsection{Why Is IOSDA Significant for High-Housing?}

3.2.1 A New Housing Supply Model Provided by IOSDA

One of the implications of IOSDA in China is its alternative funding sources from the concentred investment to the crowd-funding model, in which end 
users will participate the design decision process by paying for building their own home in a collective manner, instead of buying a built home in developers' vision. Architects will also not be in their own opaque design sphere, which often wastes resources on predicting the future market.

3.2.2 Integration on the Top-Down Mechanism (Designer's Stylistic Inputs) and the Bottom-Up Systems (Users' Customization) in High-Rise Housing Design

As long as the architectural profession exists, the architects' own stylistic preferences will inevitably persist. The bottom-up customization in housing design cannot succeed without global design management. Otherwise, it will generate global chaos, as housing products cannot be customized as isolated entities. They are collections of individual units based on negotiations between associative customizations and global set ups.

3.2.3 On-Going and Transparent Evolutionary Process of High-Rise Housing Design

Based on parametric connectivity and computational automation, IOSDA proposes iterative processes integrating real time feedback, which generates more desirable housing products based upon different individual needs. IOSDA will create open-ended housing design systems, which integrate users' feedback after occupation so that the housing design can be improved in the next project, which will significantly shorten the time of responding to the lessons learned from the past.

3.2.4 Benefits from the Parametric Design on the Ordinary Majority Instead of Realizing Extremely Expensive and Fashionable Architecture

Parametric design has been used excessively for extremely expensive signature architecture. However, when we lay back and think about the ordinary people, especially in the current economic climate. How much do they really benefit from the high-end architecture [5]? Open source design should support the collaboration between designers and users for building the users' own dwellings, not to entertain the contractual business between the designers and their clients.

Instead of reproducing another form-driven parametric housing without examining the living qualities, economic and regulatory constraints, IOSDA should substantiate parametric design tools for designing ordinary high-rise housing buildings.

3.2.5 Substantiation of the Idea of Mass Customization in High-Rise Housing in China into Applicable Design Methodologies and Tool Sets by IOSDA

Mass customization ${ }^{5}$ in housing design, instead of being abused relentlessly when the essential interest remains in the superficial formal expression which does not address the users' need, nor engage with the intricate constrains in reality. The utopian dream of mass customization for highly differentiated building parts is the result of ignoring the reality. This research project will address the culture of manufacture, marketing and business in China along the exploration of the applicable methodologies and techniques for mass customization in high-rise housing.

\subsection{What Is It All about IOSDA in Collective Housing?}

IOSDA is slightly different from OD (open design) in which the former integrates the distribution of the design source codes to both end users and multiple designers, both of whom will contribute to the overall design under the general framework set by the design leader through sophisticated processes of design control, whereas the latter solely emphasizes the participation of end users. IOSDA and OD overlap in terms of the contribution of collective design inputs beyond the sole designer's heuristic decisions. IOSDA is a big project. In order to fully grasp the scope of IOSDA, we have to clarify the following fundamental subjects.

\footnotetext{
${ }^{5}$ Mass customization was defined as the next theme of architectural discourse in the Future City Exhibition, 2006, London Barbican Centre.
} 


\subsubsection{Source Codes in IOSDA}

The source code of architectural design can be understood from many levels. At the most common level, it is the technical drawings that reveal the concealed details about how the building is put together from the design information to the material assemblies. At this level, architectural design has always been communicated by its open source. In fact, all the published architectural technical information, or the open source code, contributes to others' work in one way or another.

The level of IOSDA that we are investigating here is at the individual project level, i.e., the source code that is strategically designed for sharing and coordinating collective design inputs for the same project, which is similar to the relationship between the planning control and the architectural design, where the urban infrastructure performs as the standard interface between the global urban framework and the independent architectural design for different plots. The source codes in ISODA comprise the overall rules that govern the individual design decisions, the tools and techniques that are customized to automate some time-consuming processes and the universal component database including both geometric and non-geometric information.

\subsubsection{Interactive Interface}

Who is the source code open to? If it is to the end users, to what extent the end users will participate in the design process? If it is open to the multiple designers or organizations, how to encode and decode the design ideas with standard design descriptions? ${ }^{6}$ The key interface to communicate between human and design descriptions is computer which will only process data with the way that it understands, i.e., algorithmic expressions with the particular syntax. The design interface is crucial as it acts as the transition between the human intention and the data processing at the back stage. It drives how feasible

\footnotetext{
${ }^{6}$ Architect: Yositika Utida, Shu-Koh-Sha Architectural and Urban Design Studio.
}

and efficient the communication is between the multiple input data and the collective formal outputs.

In addition to openness and its user-friendly characteristics, the design interface must allow design leadership, sometimes even accept design arbitration, otherwise the design practice will be stuck in an anarchy state. It is necessary for the design leader to design and manipulate the rules that sort input data and organize them into some design orders, so that the housing project can be delivered efficiently.

\subsubsection{Funding Model}

If we cannot convince the developers or the government to take the risks in applying IOSDA, we should try different funding methods, such as crowd funding. Having a live interactive interface will enable the project manager to visualize the changing results effectively so that it could attract the potential crowd for purchasing the on-going design products during the development process. Financial incentives must be given to the first crowd who are willing to take the risks, e.g., primarily, time than anything else. Such new funding model will completely change the current relationships between clients, designers and users, positioning the users from the end to the frontier. The procurement of housing will enter a new era when housing projects can be initiated by professional fundraisers without developers, which is not impossible as long as this idea has no jurisdictional obstacles against the land purchase with crowd funding. Certainly, there will be many other issues, such as liabilities, IP (intelligent property) protection, donor exhaustion and financial guarantees and so on [6]. But these are not unsolvable to establish the crowd funding model for IOSDA.

\subsubsection{The Universal, Modular and Open-Ended} Architectural Sub-systems

The freedom of customization based on open source can only come true when the architecture is described as a number of sub-systems with multiple standard parts, so that the systems can change its composition over time. The branch of contemporary 
design that promotes highly specific differentiation instead of generic ambiguities is the opposite direction and cannot be implemented in IOSDA.

3.3.5 Low-Tech Construction Along with Intelligent Design Solutions

If the goal is to substantiate the IOSDA theory to design practice, design products must aim at ordinary construction means, unlike the Japanese metabolism, which resulted in extremely expensive buildings and never made a change despite its initial concept. The feasibility of IOSDA in design practice is either to avoid the physical changes to provoke any complicated neighboring disputes, or to promote a dynamic process which allows for changing input data, such as users' needs, material costs and environmental data, while the final product will still be a static building lasting for years.

\subsubsection{Parametric Modeling}

Since IOSDA needs to respond to unpredictable input data from both the end users and the multiple designers, the digital model must be parametrically constructed to allow collective reconfiguration at the building scale. Relationships between the complicated network of different parameters and formal outputs are the more essential focus than the building form itself [6]. Not only the particular parameters, but also the input data must be carefully designed as part of the parametric modeling process. In the interest of designers' personal preferences, the arbitrary graphic input must be made possible in addition to numeric input.

\subsubsection{Smart BIM}

BIM (building information modeling) model is the bridge that connects design visualization to building information, eventually grounding dynamic open source models to construction documents without consuming extra resources compared to using static models, but this is only in theory upon the fact that all BIM models are parametrically built. In practice, the changeability of BIM model is actually quite limited due to the intricate real-time links of hundreds of thousands of objects and parameters in a building scale.

Smart BIM emphasizes the ability of parametric reconfiguration of the master geometries, which leads to instant update of all the subsequent parts and elements in the BIM model, all the way through to the production information drawings, spreadsheet and illustrations. This is a challenge for the BIM designer rather than for the software programmers. The key intellectual property rests in how practical the BIM model can respond to radically different input data, e.g., the overall shape or dimension. In practice, such smart BIM process will probably involve multiple programs and establish smooth communication between different software. The communication between Rhino Grasshopper, which is a powerful design manipulation, and Revit, which can produce the construction documentation out of the information model is a case for example. We have achieved the preliminary stage of smart BIM for a singular house as showed in Figs. 3-5. Working on collective housing will be far more complicated than making the BIM model work parametrically.

\subsubsection{Database of the Components}

As mentioned in Section 3.1.1, the database of the building components is part of the shared open source code. IOSDA encourages the industry to build a model library with the participation of the industry suppliers, on the condition that rules of the modeling code are spelled out, for instance, the universal connecting interface in terms of alignment and dimensions, the standard parameter sets and the format of the models.

\subsubsection{Instant 3D Viewers}

Since IOSDA involves ordinary people other than professional designers, design communication must be carried out with understandable means of design visualization in real time. Current BIM software has embedded free BIM model viewers (such as Catia with 3D XML (Extensive Markup Language) format which can be read in word files) for end users to open 


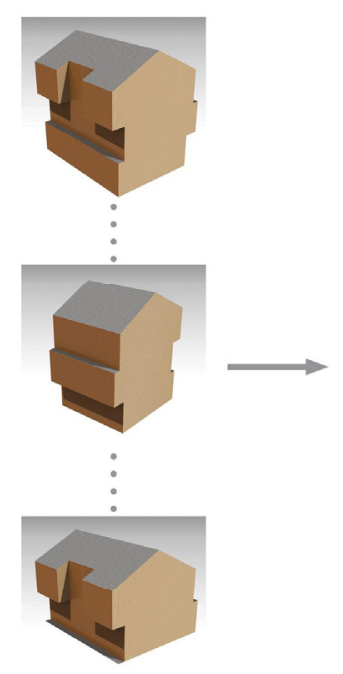

Individual house customization

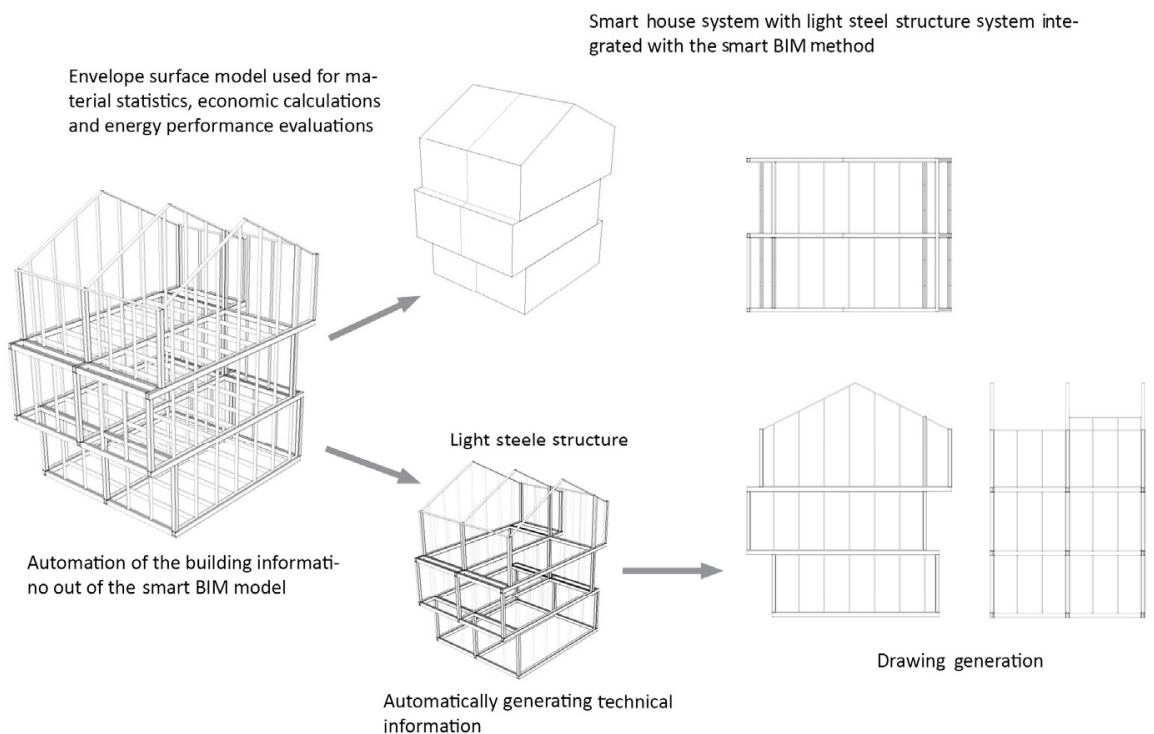

Fig. 3 Smart BIM process diagram in the single house test.
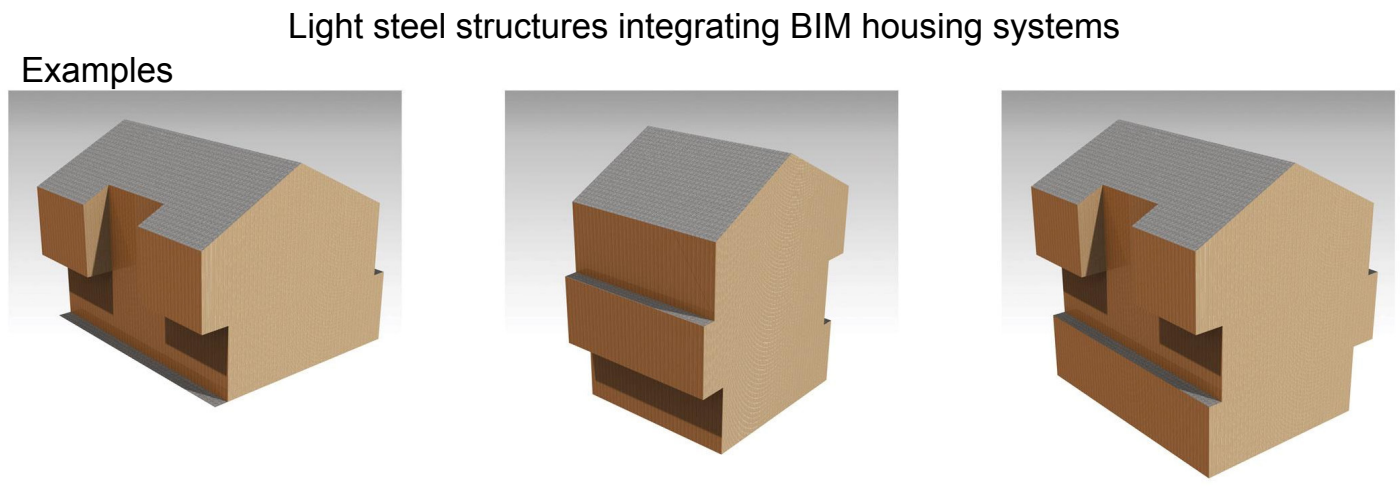

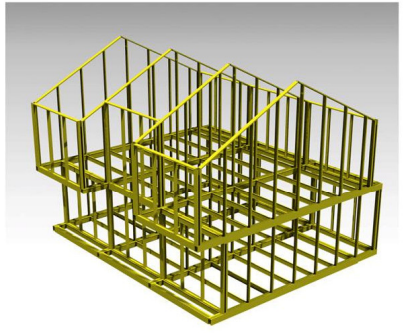

Two stories and three bays

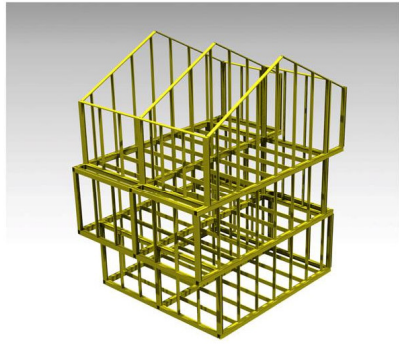

Three stories and two bays

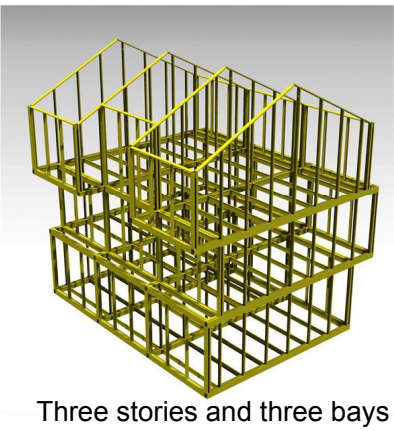

Fig. 4 Smart BIM test with different surface model input.

up the entire information model for better communication amongst different parties, whereas the traditional 2D technical drawings are only appropriate for professionals.

\subsubsection{Feedback Mechanism}

In the end, IOSDA should be open ended, allowing for uploading users' feedback from the current generation to improve the next generation in a quantifiable way. Such capability of the IOSDA model needs to be robust to avoid discrepancies caused by users' untrue input, because the model system will decide its formal response by comparing the newly input 


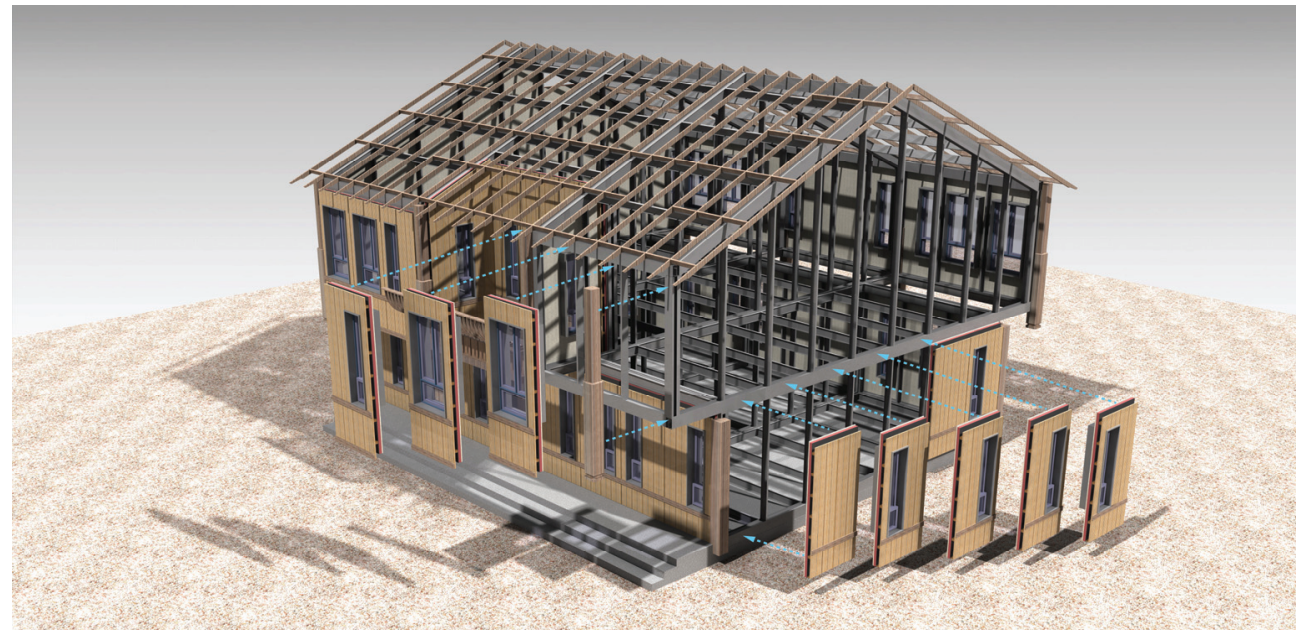

Fig. 5 Composition model of the smart BIM test.

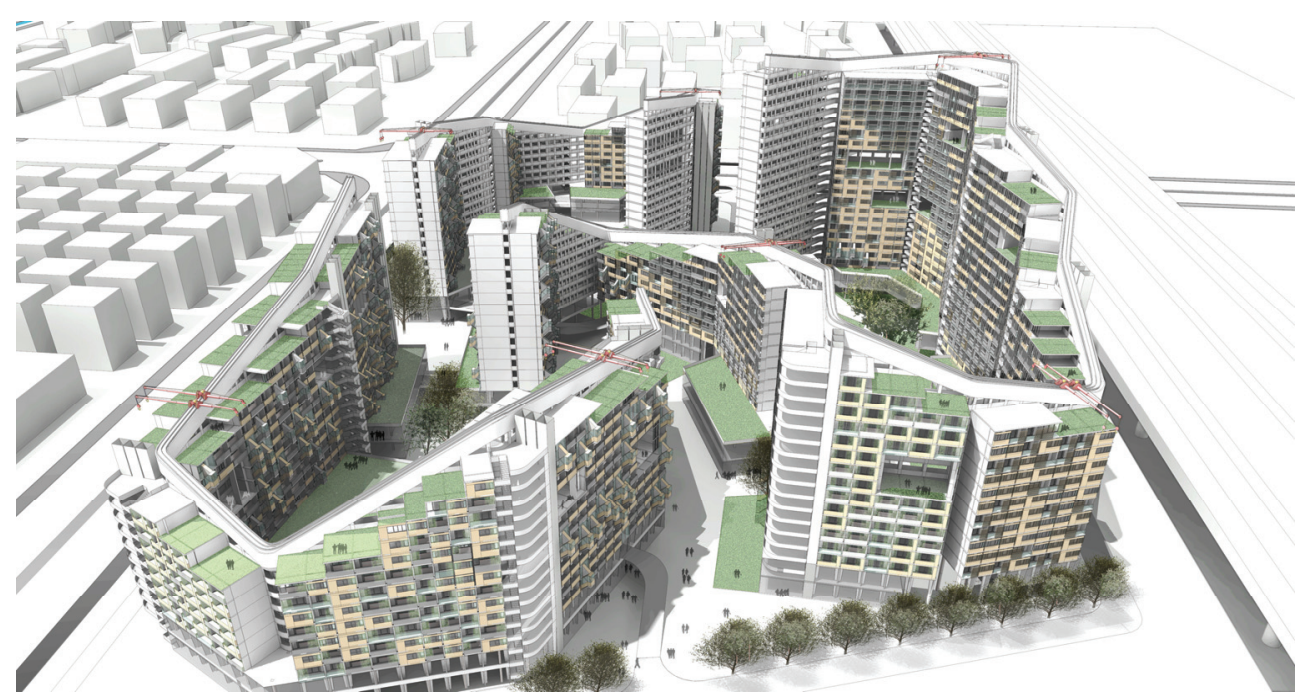

Fig. 6 Main view of the OSAD (open source architectural design) test.

Automatic Breeding Sequence

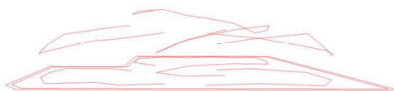

1. Input control for blobal mass

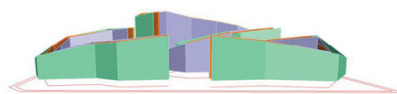

4. External surface for facade

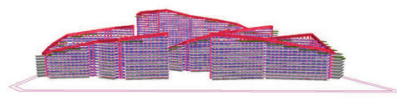

7. Roof gardens according to roof slopes

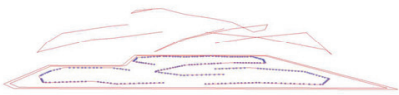

2. Subdivision to various
modular segments

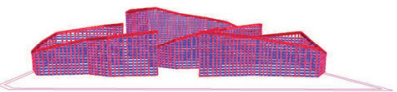

5. Corridor and Structural Frames

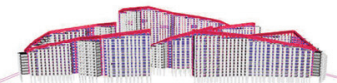

8. Load bearing walls

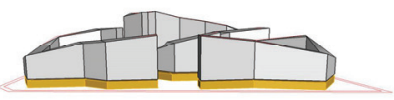

3. Massing for environmental analysis

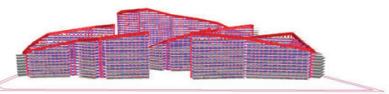

6. Floor slabs

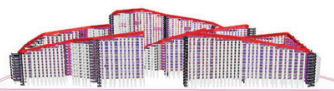

9. Circulation cores

Fig. 7 The master control surface model and the generative articulation process. 
data with the existing database and only change its configuration when the new data reach the threshold. Otherwise, the IOSDA model will become a reactive model without the ability of "thinking". The IOSDA aims at a more enduring product series within which the next generation always learn from the previous generation through processing the user feedback, or the mass data.

\subsection{How to Build Information Model in IOSDA?}

The success of implementing IOSDA needs a new way to categorize the collective housing for building a more dynamic architectural model. According to the project that we have tried to implement the theory of IOSDA (Figs. 6-10) [7], the building systems is divided into:

- Spatial driver. It refers to the master control geometries, which are often the surface models, to initiate the generative computational process based on various input information (Fig. 7);

- Structural frame. The permanent structural framework with mixed steel and prefabricated concrete is the host for accommodating different infill parts (Fig 8);

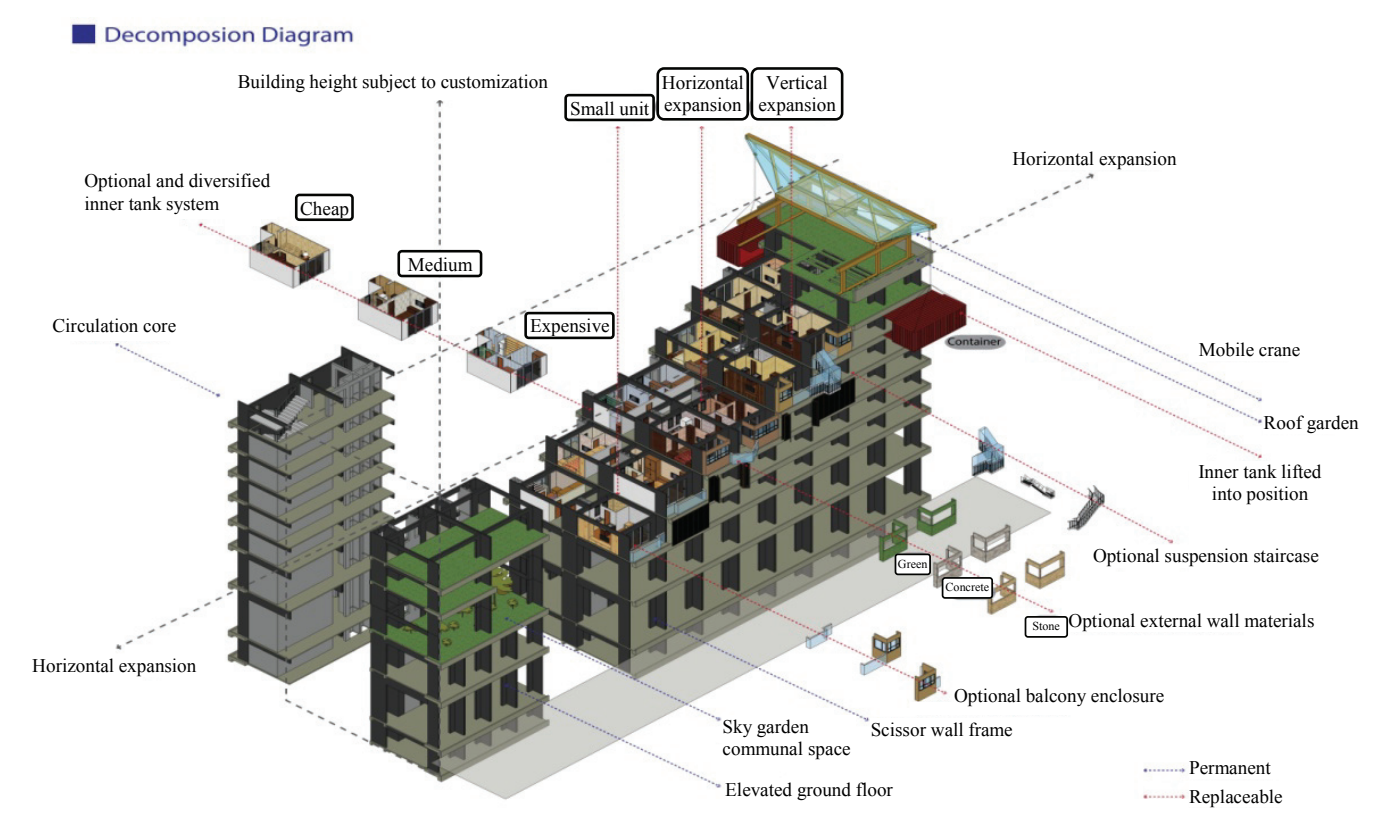

Fig. 8 System composition.

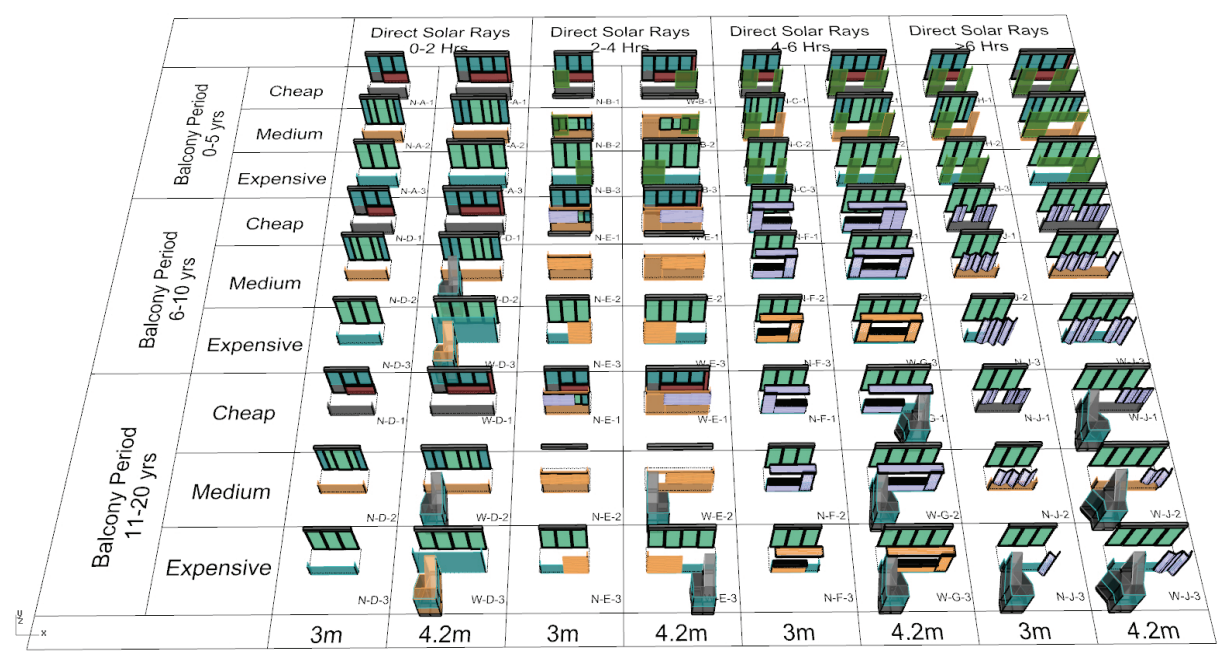

Fig. 9 Facade infill unit library. 

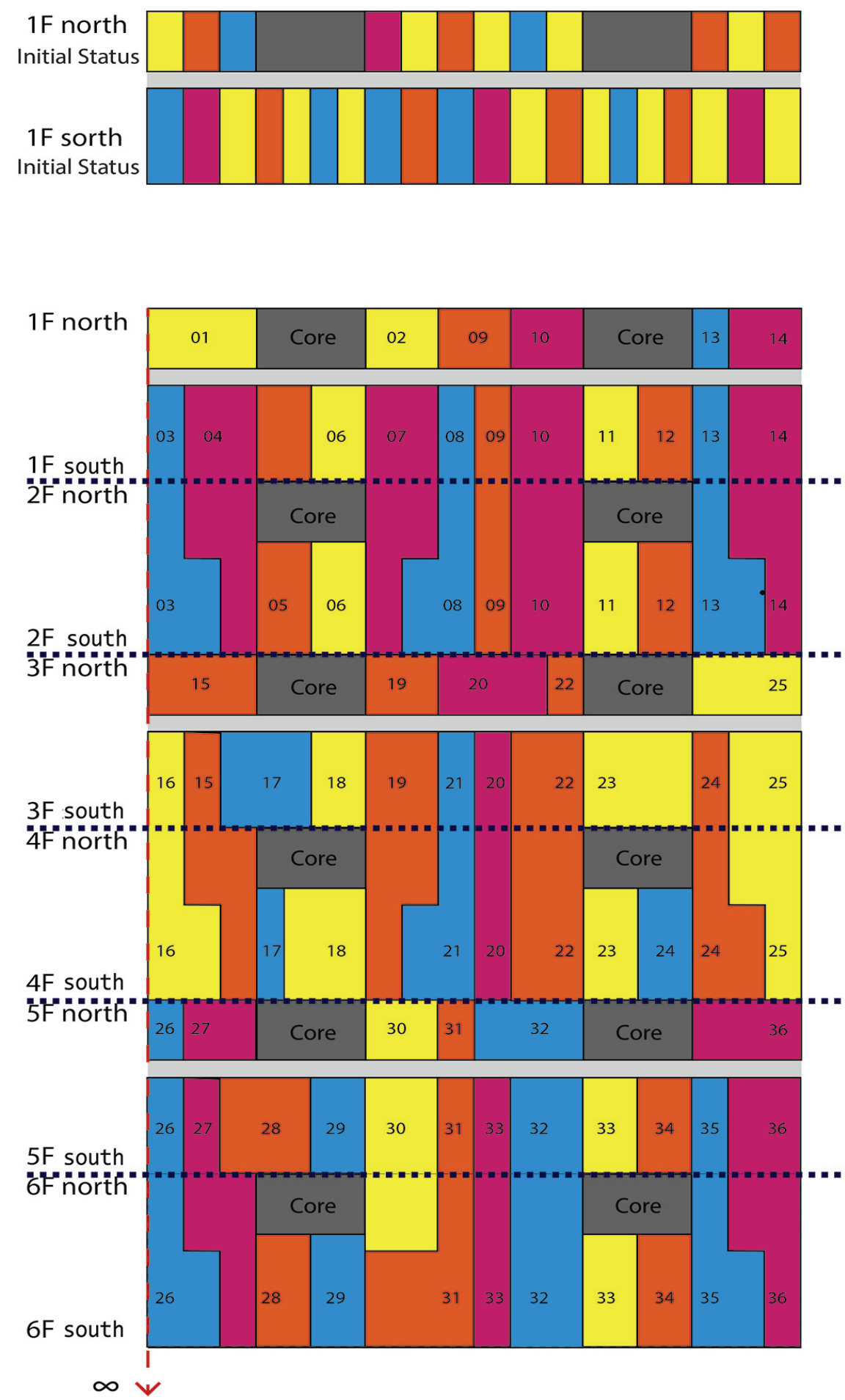

Fig. 10 The combinatory possibilities based on modular plan layout with moveable partition walls.

- Skin modules. Since the standard modules of the enclosure units have been regulated into the open source code, the adaptable facade customization will be capable for upgrading by the residents over time (Fig. 9);
- The inner partition system. The spatial layout, i.e., both the plan and the sectional division, will have to allow for flexible rearrangement according to the unpredictable users' needs and preferences (Fig. 10);

- The utility system kit. The building services, 
Whole Life-Span Open Source Architecture Diagram

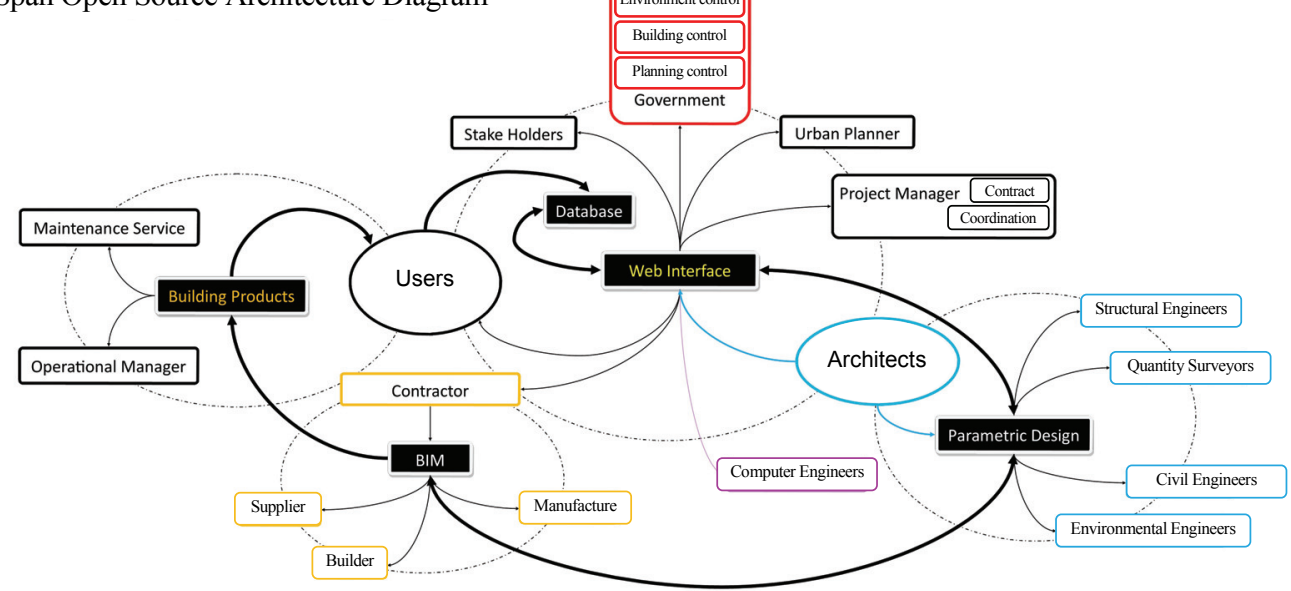

Fig. 11 Open source architecture overall system diagram.

including power, gas, water supply and discharge systems, need to be compressed into a utility kit to maximize the possibilities in supporting different spatial layout based on the open source code customization.

\section{Conclusions}

Fig. 11 summaries the relationships network of IOSDA, which involves multiple architectural designers and other parties including end users. The nonlinear workflow composes various digital means, e.g., the web interface for instant communication, the parametric software for dynamic modeling of housing systems, the BIM processes for streamlining the collective design customization with standard building components and the physical building products that contain the product information for maintenance and operations over the whole life span of the buildings. Besides, a new party will need to participate in the design processes, i.e., the algorithmic designers/programmers who codify the design into computational data flows which link the UI (user's interface) with spatial models database.

IOSDA reflects a different attitude to the design of future, which shifts from the heroic prediction of the future to the collective engagement of the present, from board proactive reaction to the capacities for new possibilities, because no matter how promising the future is predicted, uncertainties always persist. The fundamental puzzle for architects is the mission of materializing the future with inhabitable structures. The design process is often frustrated by the creative limitation and the aesthetic inertia of individual designers. IOSDA offers an alternative trajectory to tackle the future uncertainties in architecture. But, it still needs time to overcome many hurdles in real practice, such as the difficulty in persuading end users to take part in the data contribution. How many actually will bother to make the effort to participate in the design process? A counter example that drove our attention recently is that Vanke, the biggest real estate developer in the world, has recently packed up a new housing product series through optimizing the foreseeable possibilities of the housing unit layout to only four types, on the basis of their clients' feedback of the daily needs. It is yet to be tested during the current turmoil of the housing market in China, which might provide discouraging evidence that IOSDA would remain as a utopian idea in the architectural discourse. Nevertheless, we architects need to prepare ourselves with emerging theories, methodologies and technologies for applying IOSDA to real housing projects.

\section{References}

[1] Smuts, H., Van der Merwe, A., Kotze, P., and Loock, M. 
2010. "Critical Success Factors for Information Systems Outsourcing Management: A Software Development Lifecycle View." In Proceedings of the SAICSIT 2010 Conference-Fountains of Computing Research, 304-13.

[2] Lefaivre, L. 2012. "Top Down Meets Bottom-Up, Spontaneous Interventions: Design Actions for the Common Good.” Expertz.me. Accessed June 10, 2014. http://www.spontaneousinterventions.org/reading/top-do wn-meets-bottum-up.

[3] Yan, G., and Ning, D. 2010. "From Unconventional to Synthetic Computational Design." Presented at Symposium of 2010 Digital Technology Proseminar in Architecture, Shanghai, China.
[4] Sasakura, H. 2005. "Variable Infill System Rearrangement Experiment for Residence 405 at Osaka Gas Experimental Housing." Presented at The 2005 World Sustainable Building Conference, Rotterdam, the Netherlands.

[5] Yan, G., and Su, Y. 2013. "Computational Design Research for High Density Social Housing in China." Journal of Engineering Technology 2 (1): 171-81.

[6] Canada Media Fund. 2012. "Crowdfunding in a Canadian Context." Canada Media Fund. Accessed August 1, 2015. http://www.cmf-fmc.ca/documents/files/about/publicatio ns/CMF-Crowdfunding-Study.pdf.

[7] Duo, N. 2011. "From Analogical Design to Computational Design." Urban Flux Magazine 17: 98-103. 